\title{
APLIKASI GRADUATION ORGANIZER BERBASIS MOBILE PADA PERGURUAN TINGGI RAHARJA
}

\author{
Mulyati $^{1}$ \\ Astri Wulan Sari ${ }^{2}$ \\ Siti Ika Danti ${ }^{3}$ \\ Dosen Perguruan Tinggi Raharja ${ }^{1}$ \\ Mahasiswa Perguruan Tinggi Raharja Jurusan Manajemen Informatika ${ }^{2,3}$ \\ E-mail: $\underline{\text { mulyati@ raharja.info }}^{1)}, \underline{\text { astri.wulan@ raharja.info }}^{2)} \underline{\text { danti @ raharja.info }}^{3)}$
}

\begin{abstract}
ABSTRAK
Wisuda adalah kegiatan pelantikan kelulusan bagi mahasiswa yang telah menempuh masa belajar pada suatu universitas atau perguruan tinggi. Pada umumnya, wisuda dilaksanakan setiap akhir semester dalam kalender akademik. Pada Perguruan Tinggi Raharja terdapat sistem informasi penyelenggara wisuda, melalui sistem tersebut petugas hanya dapat mencatat kehadiran wisudawan/wisudawati saja, sedangkan untuk kehadiran orangtua dan tamu VIP/VVIP masih dilakukan secara manual dengan menggunakan selembar kertas.Selain itu, wisudawan/wisudawati juga kesulitan untuk mendapatkan informasi seputar acara wisuda karena belum ada sistem informasi seputar acara wisuda. Tujuan dari penelitian ini adalah untuk mengatasi kendala apa saja yang ada pada sistem informasi wisuda pada Perguruan Tinggi Raharja. Perancangan aplikasi ini menggunakan Yii Framework dan Framework Ionic dengan metode analisis SDLC (System Development Life Cycle). Dengan adanya aplikasi graduation organizer online ini diharapkan wisudawan/wisudawati akan lebih mudah mendapatkan informasi acara wisuda.
\end{abstract}

Kata kunci: aplikasi, informasi, organizer, wisuda.

\begin{abstract}
Graduation was an inauguration event of graduation for students who have studied at a university or college. Generally, the graduation was held at the end of each semester in the academic calendar. At Raharja Colleges there was a graduation organizer information system, through the system officers only could records the presence of graduates. Whereas for the presence of parents and VIP/VVIP guests still done manually that was using a sheet of paper to records presence of parents and VIP/VVIP guests. In addition, graduates also difficult got information about the graduation event because there is no information system about the graduation event. The purpose of this research was overcoming any obstacle that exist in graduation information system at Raharja Colleges. The design of this application used Yii Framework and Ionic Framework with SDLC (System Development Life Cycle) analysis method. So with the application of online graduation organizer were expected by graduates would be easy got information of graduation event.
\end{abstract}

Keyword : Application, Information, Organizer, Graduation.

\section{PENDAHULUAN}

Sebelum membuat sistem terlebih dahulu dibuat suatu perancangan sistem. Prototype sistem merupakan salah satu contoh dari perancangan suatu sistem. Perancangan sebuah sistem diperlukan untuk mempermudah programmer dalam membuat sistem agar sesuai dengan kebutuhan user. Dalam suatu perguruan tinggi negeri ataupun swasta pasti akan melakukan wisuda untuk mahasiswa yang telah selesai melakukan proses pembelajaran. Pada umumnya waktu pelaksanaan wisuda dilakukan pada akhir dari waktu akademik baik pada semester genap maupun ganjil pada suatu perguruan tinggi. 
Untuk mempermudah waktu pengaksesan dalam acara wisuda perlu adanya suatu aplikasi berbasis online agar wisudawan mendapatkan informasi up to date mengenai wisuda dengan menggunakan gadget di manapun dan kapanpun dengan menggunakan mobile application. Objek yang dilakukan dalam penelitian yaitu Perguruan Tinggi yang berada di wilayah Kota Tangerang yaitu Perguruan Tinggi Raharja. Hal tersebut dikarenakan peserta wisudawan/wisudawati Perguruan Tinggi Raharja sulit mendapatkan informasi mengenai wisuda dan untuk membantu pihak dari akademik melakukan pengarsipan data-data wisudawan/wisudawati.

Peneliti merancang aplikasi graduation organizer online untuk memudahkan wisudawan/wisudawati mendapatkan informasi terkait data wisudawan, denah duduk, susunan acara wisuda, galeri foto, video, dan absensi wisudawan. Selain itu, aplikasi graduation organizer dapat membantu operator memantau absensi dan jumlah kehadiran wisudawan, serta mempermudah admin menginput data wisudawan.

\section{PERMASALAHAN}

Sesuai dengan pembahasan penelitian acara wisuda pada Perguruan Tinggi Raharja yang telah diuraikan sebelumnya, dapat ditarik beberapa permasalahan sebagai berikut :

1. Bagaimana sistem acara wisuda pada Perguruan Tinggi Raharja yang berjalan saat ini?

2. Apakah wisudawan mengalami kesulitan dalam mendapatkan informasi perihal acara wisuda pada Perguruan Tinggi Raharja?

3. Bagaimana perancangan sistem aplikasi online graduation organizer pada Perguruan Tinggi Raharja?

\section{TINJAUAN PUSTAKA}

\section{Definisi sistem}

Menurut Luwig Von Bertalanfly dalam Maulani dkk. (2016:3), "Sistem merupakan seperangkat unsur-unsur yang terkait dalam suatu antar relasi diantara unsur-unsur tersebut dan dengan lingkungan.[1]"

\section{Definisi informasi}

Menurut George H.B \& William S.H dalam Maulani dkk. (2016:3), "Informasi adalah data diolah sehingga dapat dijadikan dasar untuk pengambilan keputusan.[1]"

\section{Definisi data}

Menurut Aris dkk. (2016:74), "Sumber informasi adalah data. Data adalah kenyataan yang menggambarkan suatu kejadian-kejadian dan kesatuan nyata. Kejadian (event) adalah sesuatu yang terjadi pada saat tertentu. Kesatuan nyata (fact and entity) adalah berupa suatu objek nyata seperti tempat, benda, dan orang yang betul-betul ada dan terjadi.[2]"

\section{Definisi wisuda}

Menurut Mulyadi (2013:33), "Wisuda merupakan proses pelantikan kelulusan mahasiswa yang telah menempuh masa belajar pada suatu perguruan tinggi.[3]"

\section{Definisi event organizer}

Menurut Londa (2014:1), "Pengertian sederhana tentang Event Organizer adalah pengelola suatu kegiatan (pengorganisir acara). Setiap kegiatan yang diselenggarakan bertujuan untuk memperoleh keuntungan di kedua belah pihak, baik penyelenggara maupun yang hadir pada saat kegiatan berlangsung.[4]"

\section{Definisi aplikasi mobile}

Menurut Utomo (2010:47), "Aplikasi mobile adalah aplikasi yang dikembangkan untuk perangkat handheld seperti personal digital assistant (PDA), enterprise digital assistant atau telepon seluler.[5]"

\section{LITERATURE REVIEW}

Banyak literature review atau penelitian yang sebelumnya dilakukan berkenaan dengan aplikasi event organizer online berbasis mobile. Beberapa literature review tersebut adalah sebagai berikut : 
1. Penelitian yang dilakukan oleh Farid Ardi Wijaya, Mochammad Arifin dan Sulistiowati dengan judul "Rancang Bangun Aplikasi Penjadwalan Penyewaan Peralatan Event Organizer (Studi Kasus pada PT Geo Given Visi Mandiri)". Metode yang digunakan untuk menganalisis data yaitu System Development Life Cycle (SDLC). Sistem tersebut dapat menghasilkan laporan yang dibutuhkan oleh perusahaan dalam mengetahui dalam kegiatan pemesanan event maupun kegiatan penyewaan peralatannya, penyusunan jadwal hingga pengembalian dan pembayaran terhadap pihak terkait.

2. Penelitian yang dilakukan oleh Agung Wahana, Adam Faroqi, dan Egi Adtya Pratama Putra dengan judul penelitian "Pembangunan Sistem Event Calendar pada Platform Android dengan Dukungan Web Service". Tujuan penelitian ini adalah untuk membangun sistem event calendar pada platform android dengan dukungan web service yang membantu para pengguna telepon seluler berbasis andorid untuk mengetahui informasi tentang kegiatankegiatan yang akan diselenggarakan di kota Bandung secara up to date disertai dengan peta lokasi kegiatan dengan dukungan web service.

3. Penelitian yang berjudul "Pengembangan Aplikasi Denpasar Festival pada Platform Mobile" yang dilakukan oleh I Gede Harsemadi, I Made Adi Purwantara, dan Ni Made Dewi Purnama Sari. Tujuan dari penelitian ini adalah agar menghasilkan aplikasi yang berguna sebagai sarana informasi oleh wisatawan yang hendak berkunjung ke Denpasar. Hasil akhir dari penelitian ini berupa aplikasi yang dapat diimplementasikan pada platform mobile dengan sistem operasi android yang berisikan informasi dan gambar terkait acara Denpasar Festival.

4. Penelitian dengan judul "Pembuatan Aplikasi Event Organizer Clover Berbasis Android" yang dilakukan oleh Andreanus Agung, Silvia Rostianingsih, dan Agustinus Noertjahyana. Penelitian ini dilakukan dengan tujuan untuk membuat aplikasi yang dapat menangani pendataan anggota, penjadwalan anggota, absensi anggota, hingga dokumentasi pada website setelah event berlangsung.

5. Penelitian yang dilakukan oleh Jefferson Setiawan, Edy Kristianto, dan Fredicia dengan judul penelitian "Implementasi Push Notification pada Informasi Perkuliahan dan Kegiatan Mahasiswa Berbasis Android". Tujuan penelitian ini adalah untuk memudahkan mahasiswa dalam mendapatkan informasi perkuliahan dan informasi kegiatan mahasiswa, yang terintegrasi dengan smartphone android. Aplikasi ini dikembangkan dengan menggunakan pendekatan $S D L C$, yaitu model waterfall.

6. Penelitian yang dilakukan oleh Ardiansyah dengan judul "Analisis dan Perancangan Sistem Manajemen Event Berbasis Mobile Push Notification". Hasil dari penelitian ini yaitu sistem manajemen event yang bisa mengelola sebuah acara mulai dari sisi administrator pihak EO hingga sisi user yang menggunakan antarmuka berbasis piranti mobile khususnya. Sehingga user dapat dengan mudah melakukan registrasi sekaligus melakukan pembayaran event tersebut.

7. Penelitian yang dilakukan oleh Fitriani Bakri dan Irawati dengan judul penelitian "Rancang Bangun Meeting Managemet System Berbasis Mobile". Aplikasi ini dapat menyampaikan informasi meeting mulai dari rincian meeting, waktu, tanggal, tempat meeting beserta lokasi meeting dalam model peta google maps. Namun, aplikasi ini hanya menampilkan informasi meeting, peserta meeting tidak dapat melakukan konfirmasi ketidakhadiran.

8. Penelitian dengan judul "Aplikasi Sistem Informasi Pendaftaran Wisuda Berbasis Online Studi Kasus FST UIN Syarif Hidayatullah Jakarta" yang dilakukan oleh Nuryasin. Penelitian ini menghasilkan aplikasi yang dapat melayani pendaftaran wisuda di FST UIN Syarif Hidayatullah Jakarta secara online. Melalui aplikasi sistem informasi pendaftaran wisuda ini mahasiswa dapat mengisi langsung form pendaftaran wisuda secara online. Mahasiswa tinggal mengakses website yang telah dibuat kemudian mengisi form aplikasi untuk melakukan pendaftaran wisuda.

9. Penelitian yang dilakukan oleh Mulyadi dengan judul "Rancang Bangun Sistem Pendaftaran Wisuda (Studi Kasus : STIKOM Dinamika Bangsa Jambi)". Prosedur pendaftaran wisuda membutuhkan waktu dan proses administrasi yang cukup panjang, sehingga perlu dibuat sebuah sistem pendaftaran wisuda yang lebih efisien. Penelitian ini dilakukan dengan tujuan untuk menganalisis kebutuhan sistem dan merancang sistem pendaftaran wisuda dengan pendekatan berorientasi objek. 
10. Penelitian yang dilakukan oleh Kartika Indayani, Catur Iswahyudi, dan Erfanti Fatkhiyah dengan judul penelitian "Aplikasi Mobile Alumni Center (Studi Kasus di Institut Sains \& Teknologi AKPRIND)". Masalah yang diteliti dalam penelitian ini adalah tentang membangun suatu aplikasi mobile yang membantu proses pendataan Alumni Institut Sains \& Teknologi AKPRIND Yogyakarta secara lengkap dan dapat diperbaharui dengan mudah kapan saja, yang meliputi data personal, data tempat bekerja dan galeri photo Alumni.

Dari sepuluh literature review tersebut, terdapat beberapa perbedaan yaitu penelitian ini membahas tentang pengembangan sistem graduation organizer online pada Perguruan Tinggi Raharja, sehingga sistem tersebut dapat berjalan sesuai kebutuhan dan dapat diakses dengan mudah tanpa adanya kendala.

\section{PEMBAHASAN}

Untuk mengatasi permasalahan yang sudah dipaparkan di atas yaitu dengan merancang aplikasi sistem Online Graduation Organizer menggunakan Mobile Application. Adapun prosedur sistem yang diusulkan sebagai berikut :

Admin dan operator dapat login dengan memasukkan username dan password yang telah terdaftar pada sistem. Kemudian, admin dan operator dapat melakukan absensi pada gladi kotor, gladi bersih, serta absen di hari wisuda. Admin dan operator juga dapat melakukan absensi pada orang tua dan tamu VIP/VVIP, sedangkan wisudawan dapat login SSO (Single Sign On) pada sistem dengan email Rinfo. Setelah berhasil login, wisudawan dapat memperoleh informasi seputar wisuda pada sistem tersebut. Wisudawan juga dapat melihat data-data wisudawan.

\section{Use Case Diagram}

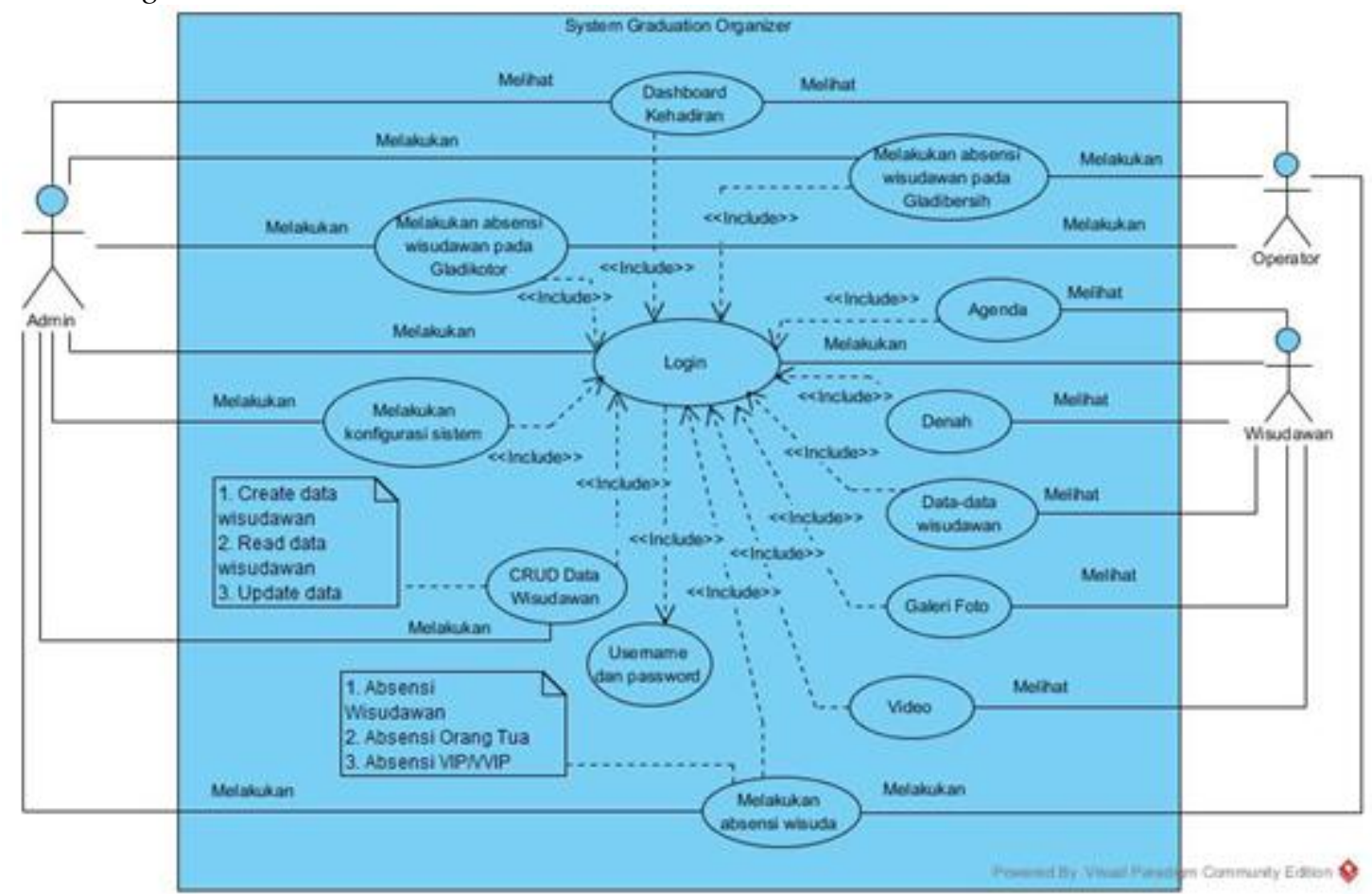

Gambar1. Use Case Diagram Admin dan operator dapat login dengan memasukkan username dan password yang telah terdaftar 


\section{Activity Diagram}

1. Activity Diagram Admin

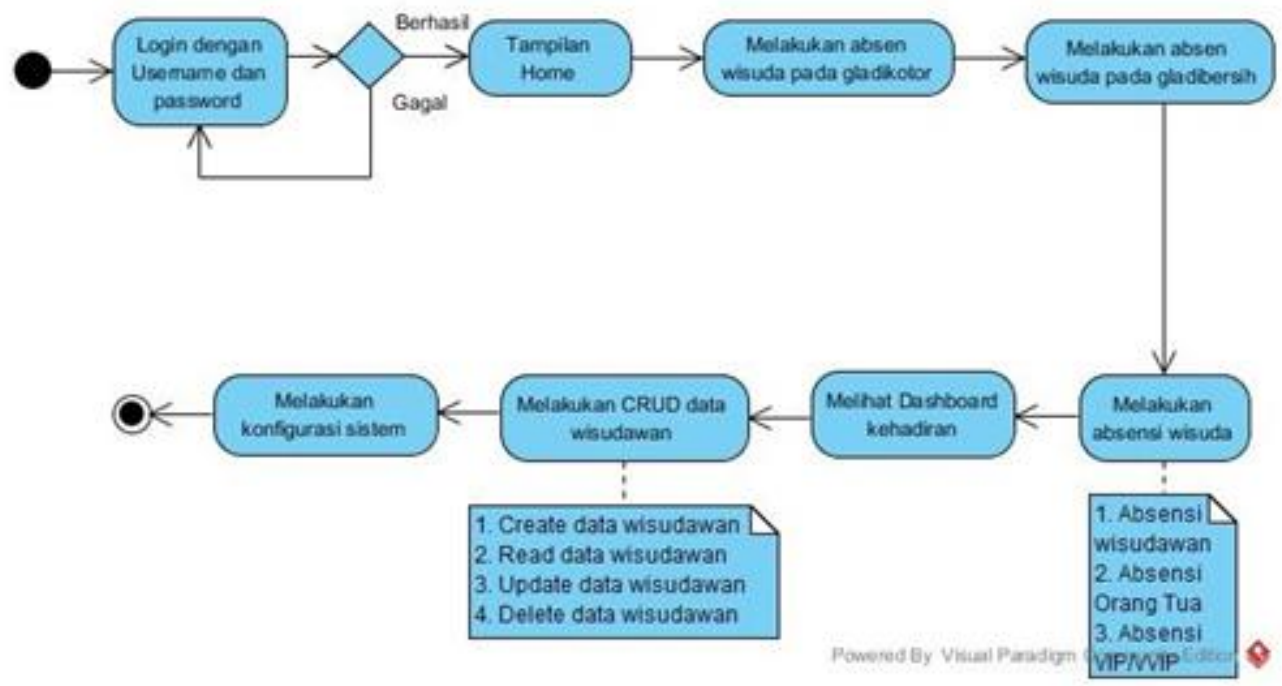

Gambar2. Activity Diagram untuk Admin

Pada activity diagram, admin harus melakukan login terlebih dahulu dengan menggunakan username dan password agar dapat mengakses sistem Graduation Organizer. Setelah berhasil login, admin akan dialihkan ke halaman home. Selanjutnya, admin dapat melakukan absensi wisuda pada gladi kotor, gladi bersih, dan absensi di hari wisuda. Pada absensi acara wisuda, admin dapat melakukan absensi wisudawan, absensi orang tua, serta melakukan absensi VIP/VVIP. Kemudian admin dapat melihat dashboard kehadiran wisudawan.

1. Activity Diagram Operator

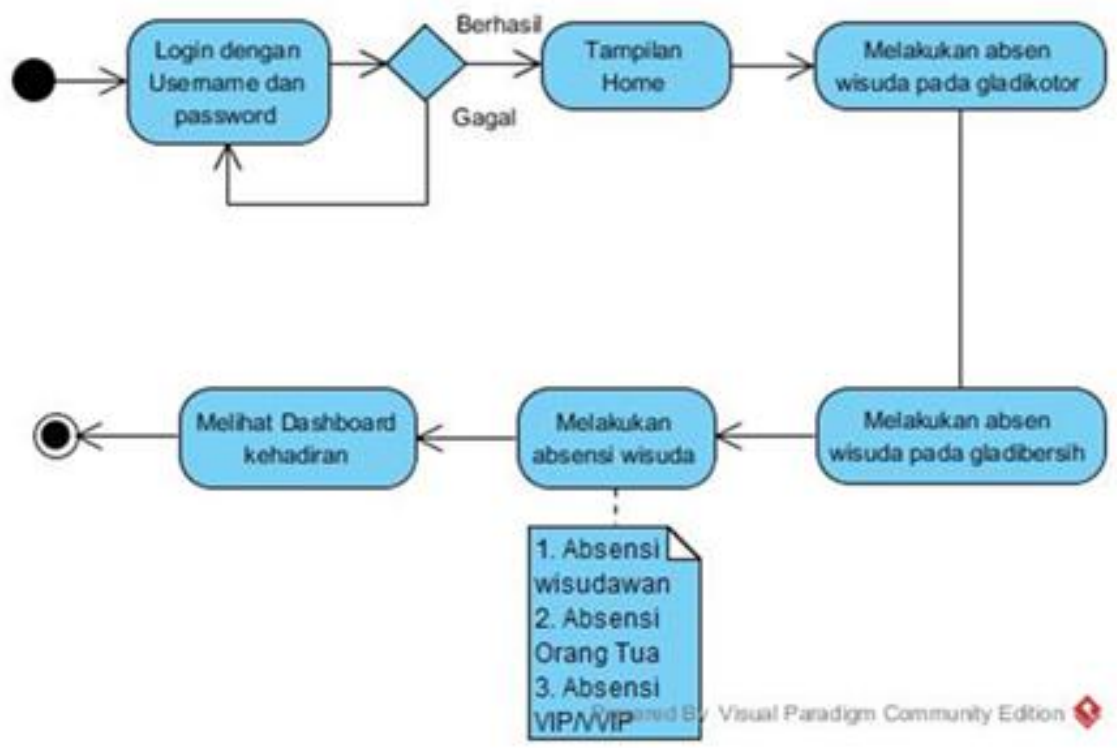

Gambar3. Activity Diagram untuk Operator

Pada activity diagram, operator harus melakukan login terlebih dahulu dengan menggunakan username dan password, sehingga dapat mengakses sistem. Setelah berhasil login, operator akan dialihkan ke halaman home. Kemudian operator dapat melakukan absensi wisuda pada gladi kotor, gladi bersih, dan melakukan absensi di hari wisuda. Pada absensi wisuda operator dapat melakukan absensi wisudawan, absensi orang tua, serta melakukan absensi VIP/VVIP. 
1. Activity Diagram Wisudawan

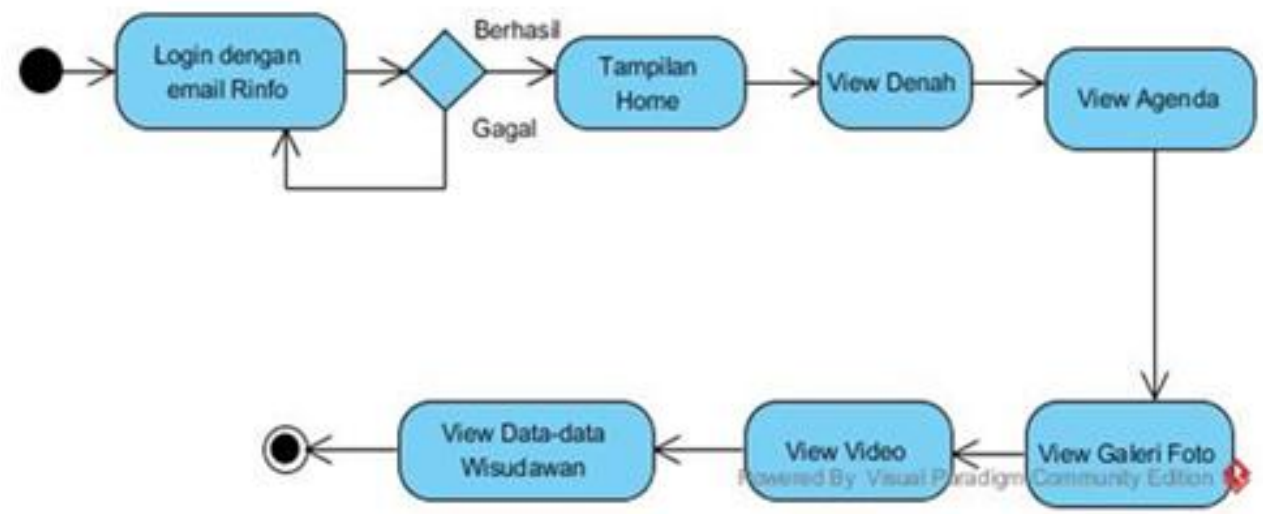

Gambar4. Activity Diagram Untuk Wisudawan

Pada activity diagram, wisudawan harus melakukan login terlebih dahulu menggunakan email Rinfo sebelum dapat mengakses sistem Graduation Organizer. Setelah berhasil login, wisudawan akan melihat tampilan halaman home. Kemudian wisudawan dapat melihat denah gedung wisuda, melihat susunan acara wisuda pada menu agenda, dan melihat galeri foto yang terdapat kumpulan foto-foto wisudawan. Setelah itu wisudawan dapat melihat video wisudawan dan melihat data-data wisudawan.

\section{Sequence Diagram}

1. Sequence Diagram Admin

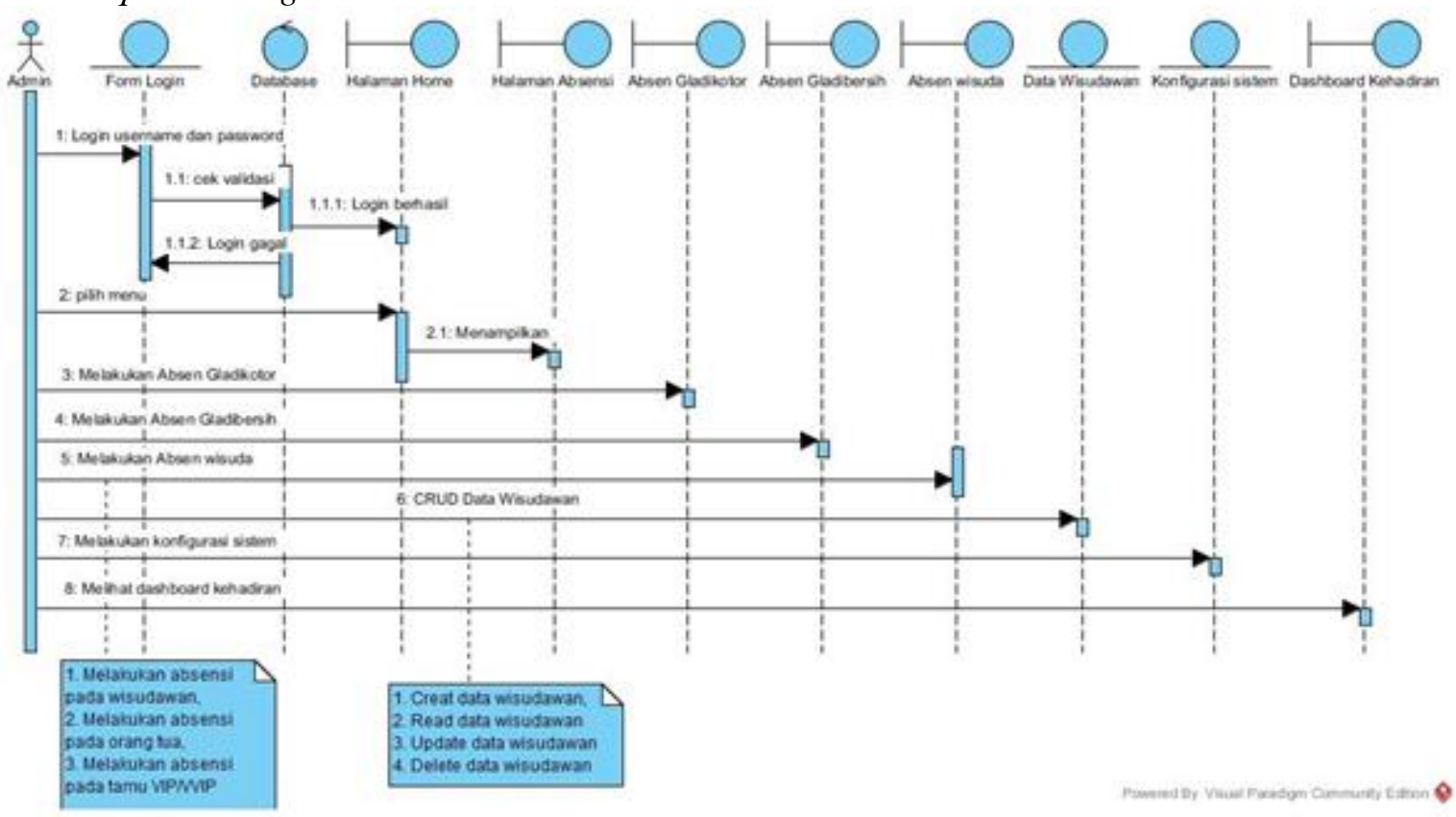

Gambar5. Sequence Diagram untuk Admin

Pada sequence diagram, admin melakukan login terlebih dahulu dengan username dan password sebelum masuk ke sistem. Kemudian database akan melakukan validasi email. Setelah berhasil login, akan masuk ke halaman home. Selanjutnya admin dapat melakukan absensi wisudawan, melakukan CRUD (Create Read Update Delete) data wisudawan, dan melihat dashboard kehadiran pada sistem. 
1. Sequence Diagram Operator

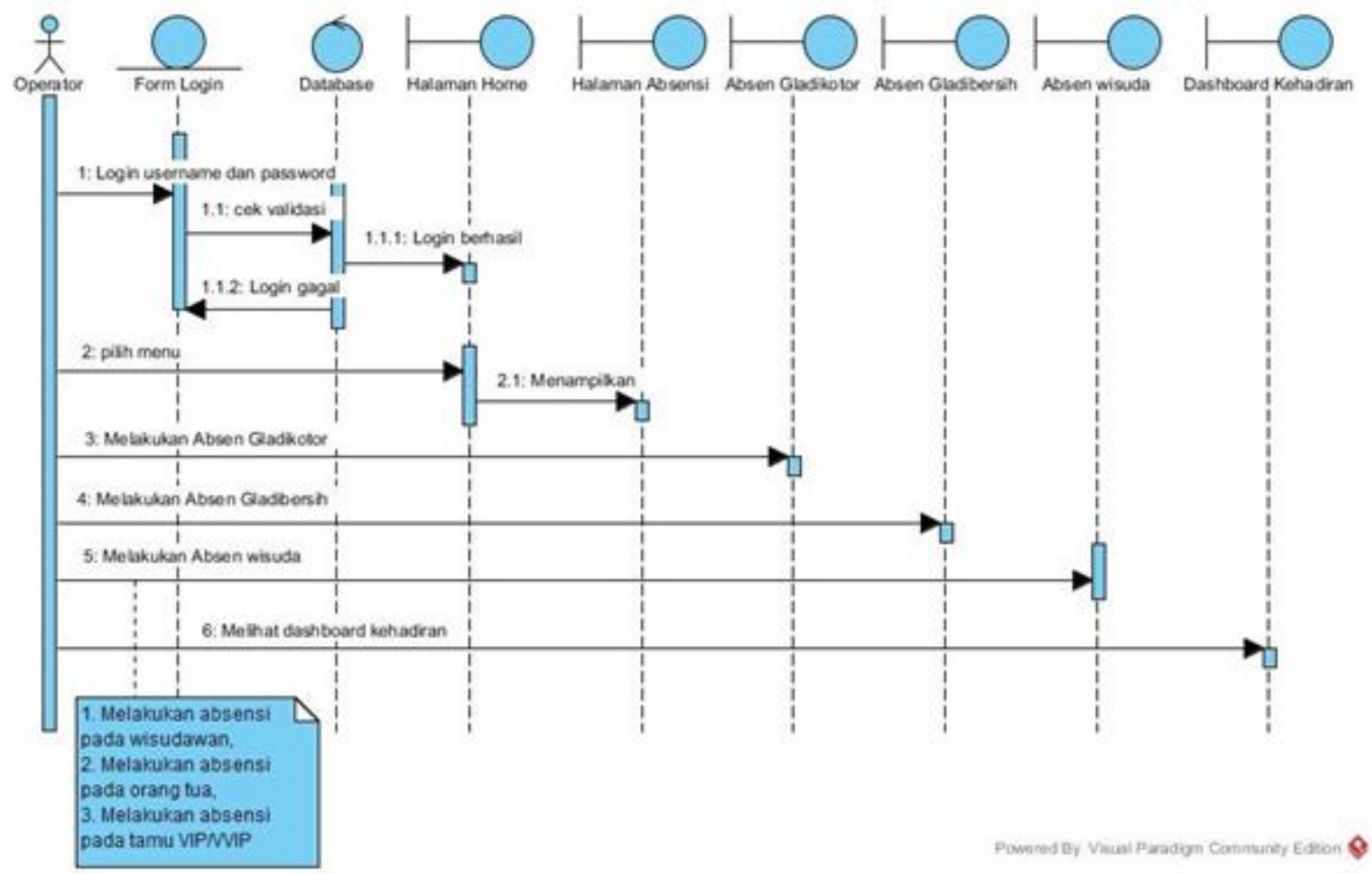

Gambar6. Sequence Diagram untuk Operator

Diagram di atas menjelaskan bahwa operator harus melakukan login dengan username dan password terlebih dahulu sebelum masuk ke sistem. Lalu database akan melakukan validasi email. Setelah berhasil login, kemudian akan masuk ke halaman home. Setelah itu operator dapat melakukan absensi wisudawan, dan melihat dashboard kehadiran pada sistem.

1. Sequence Diagram Wisudawan

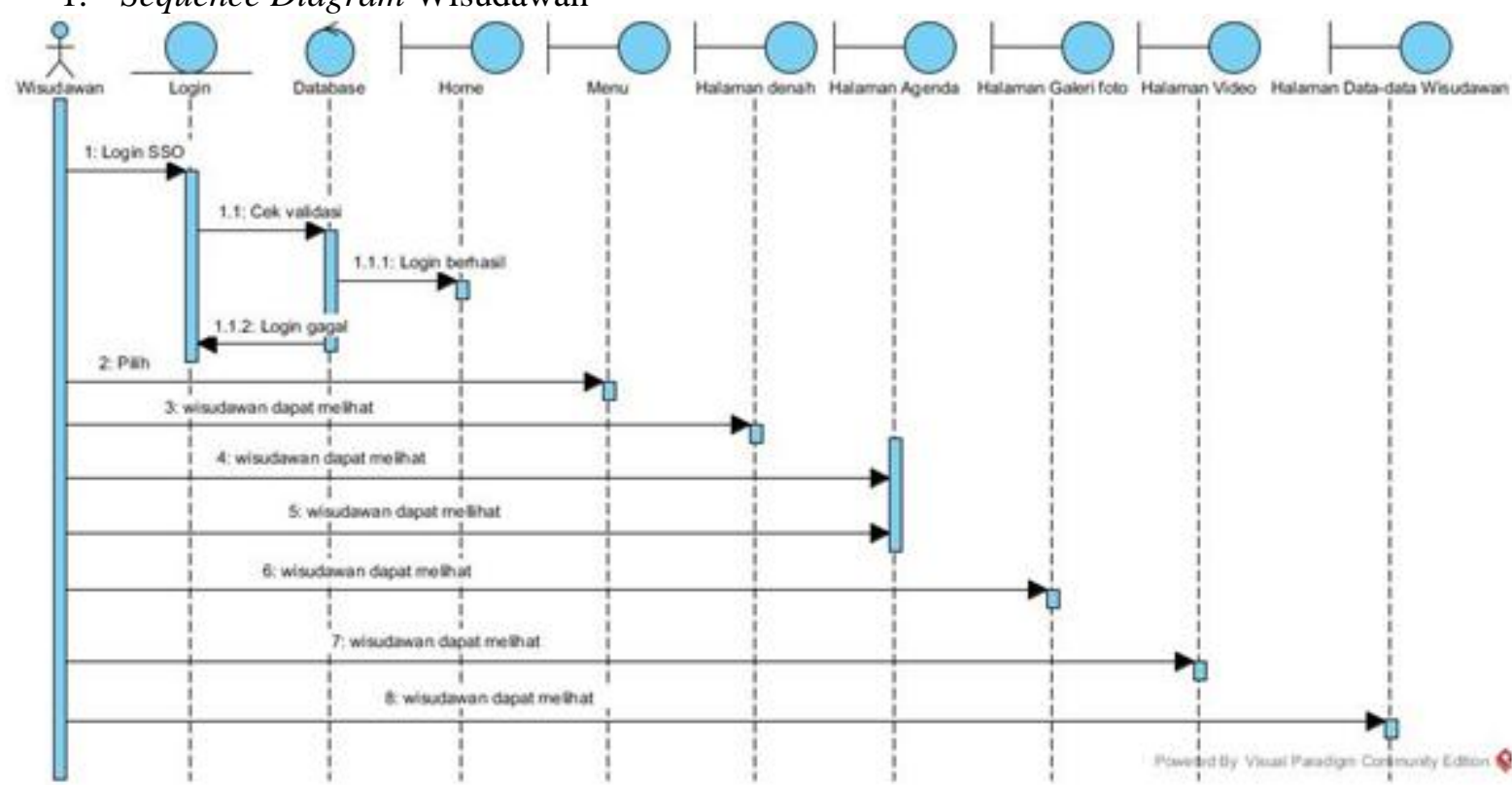

Gambar7. Sequence Diagram untuk Wisudawan

Sequence diagram di atas menjelaskan bahwa wisudawan melakukan login SSO dengan email Rinfo terlebih dahulu sebelum masuk ke sistem. Kemudian database akan 
melakukan validasi email. Setelah berhasil login, akan masuk ke halaman home. Selanjutnya wisudawan dapat melihat denah, agenda, galeri foto, video, dan data-data wisudawan.

\section{Rancangan Basis Data}

Basis data merupakan media penyimpanan data yang digunakan dalam aplikasi untuk membantu pemrograman dalam menampilkan data. Berikut adalah rancangan basis data yang digunakan dalam sistem Graduation Organizer.

\section{Class Diagram}

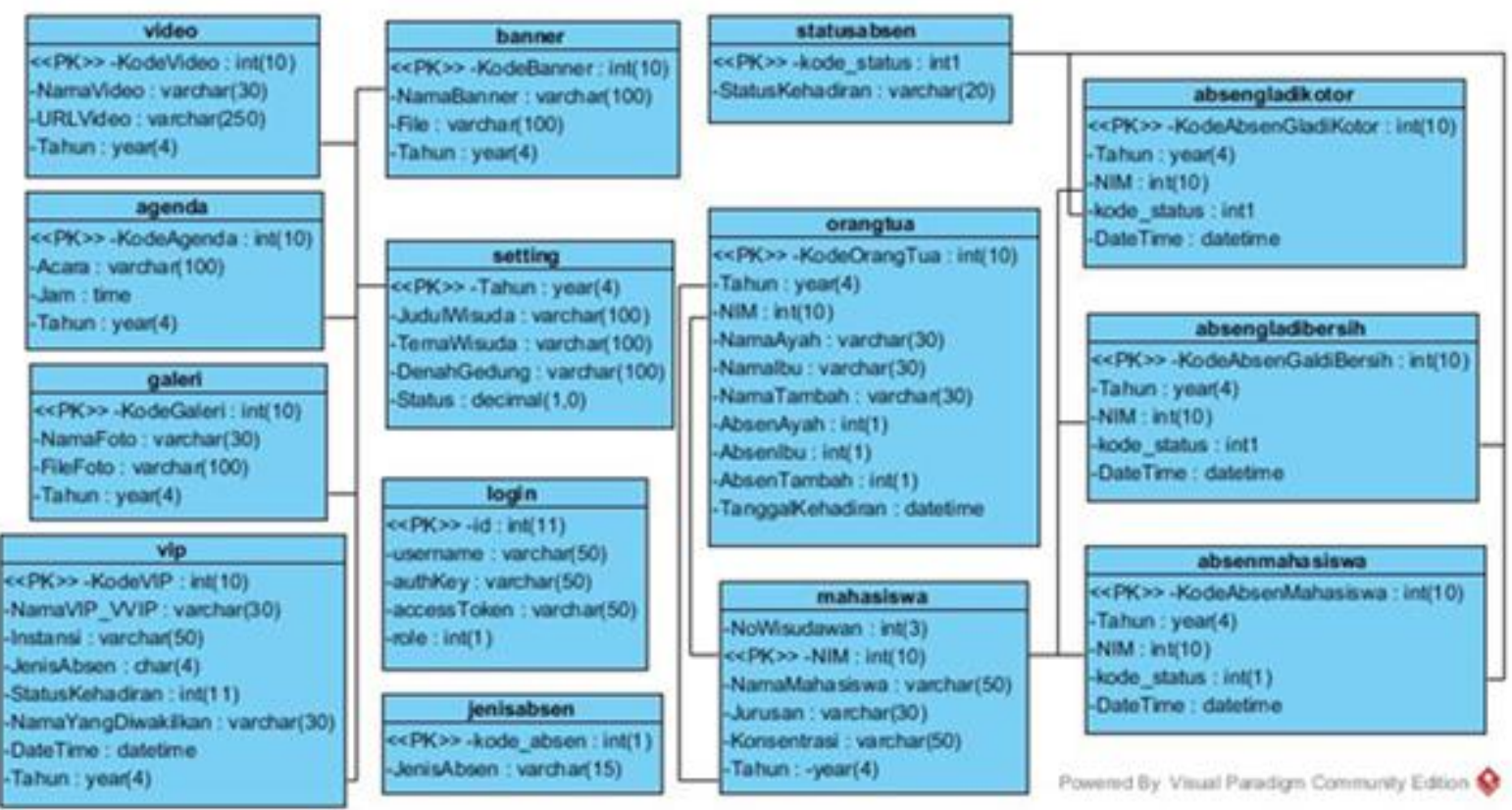

Gambar8. Class Diagram

\section{IMPLEMENTASI}

1. Halaman login web (admin dan operator)

Pada tampilan halaman login sistem, admin dan operator melakukan login dengan menggunakan username dan password yang telah terdaftar.

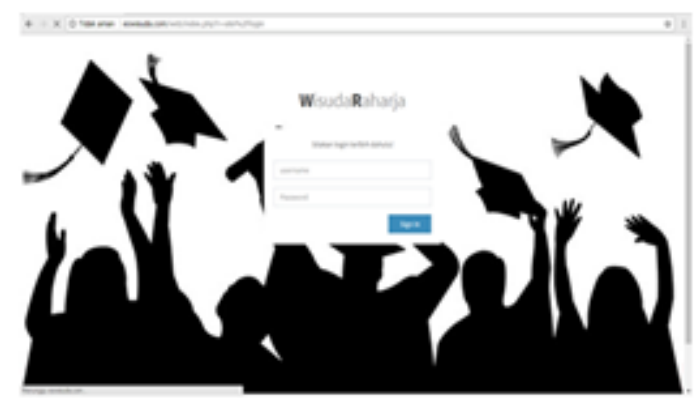

Gambar9. Halaman login web

2. Halaman home web (admin dan operator)

Tampilan home dapat diakses jika admin dan operator berhasil melakukan login dengan username dan password yang telah terdaftar. 


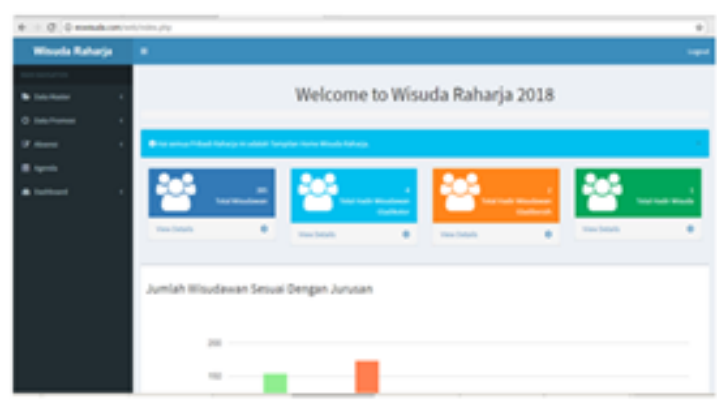

Gambar10. Halaman home web

3. Halaman data wisudawan

Pada halaman data wisudawan berisikan data wisudawan yang terakhir. Pada halaman tersebut, admin dapat melakukan "add data wisudawan" pada button "add data wisudawan", setelah admin melakukan klik "add data wisudawan" maka akan tampil halaman create data wisudawan.

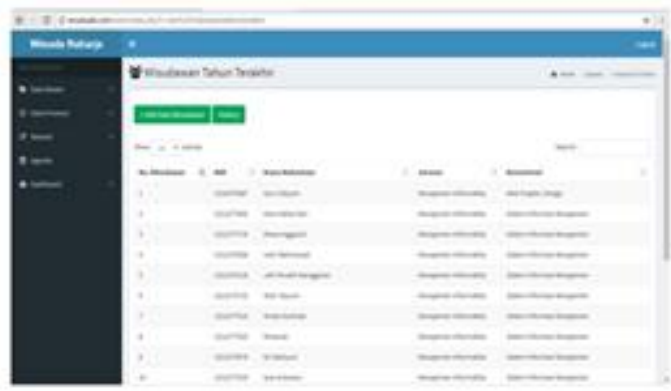

Gambar11. Halaman data wisudawan

4. Halaman create data wisudawan (admin)

Pada halaman create data wisudawan, admin dapat menambah data wisudawan dengan mengisi NIM, nama mahasiswa, jurusan, konsentrasi, no. wisudawan, dan tahun.

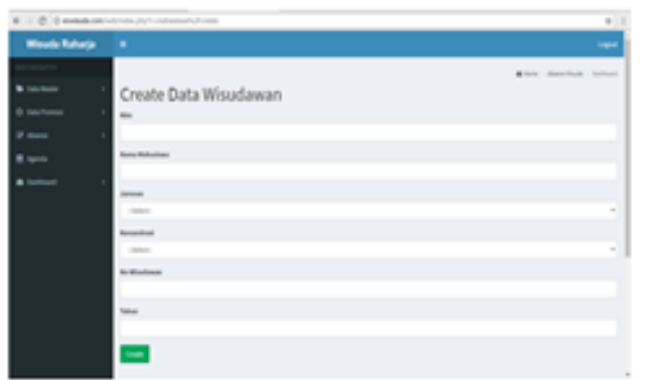

Gambar12. Halaman create data wisudawan (admin)

5. Halaman absen wisudawan

Pada tampilan halaman absen wisudawan, admin dan operator dapat mengisi data kehadiran wisudawan dengan melakukan klik "hadir". 


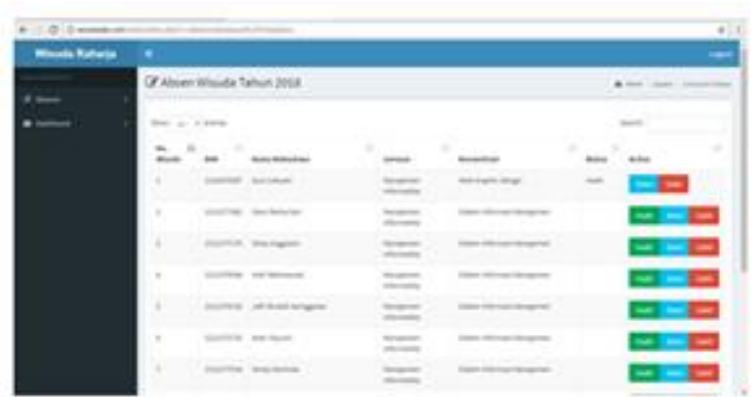

Gambar13. Halaman absen wisudawan

6. Halaman dashboard kehadiran

Pada halaman dashboard kehadiran, admin dan operator dapat menerima informasi presentase kehadiran wisudawan.

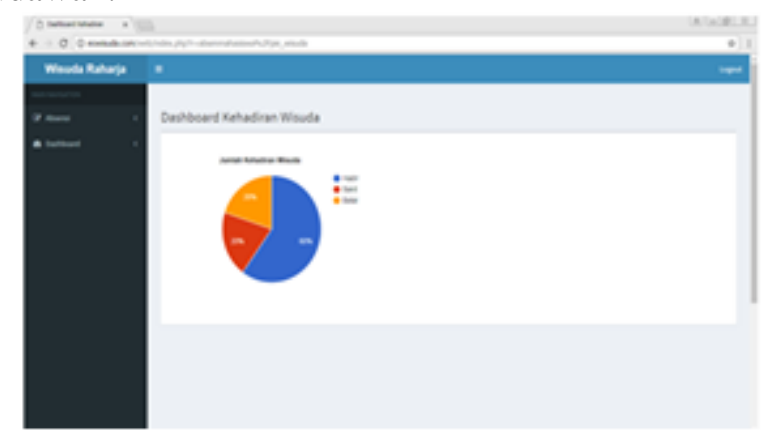

Gambar14. Halaman dashboard kehadiran

7. Halaman login (wisudawan)

Tampilan login pada Mobile App. Pada tampilan tersebut wisudawan melakukan login SSO menggunakan akun Raharja Info.

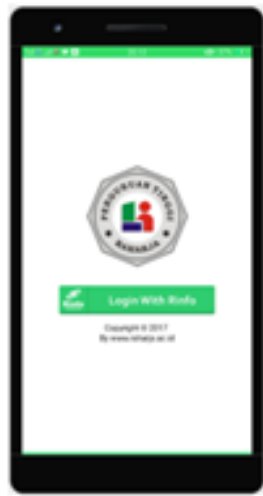

Gambar15. Halaman login (wisudawan)

8. Halaman utama (wisudawan)

Tampilan menu utama (home) pada Mobile App setelah wisudawan berhasil melakukan login SSO. 


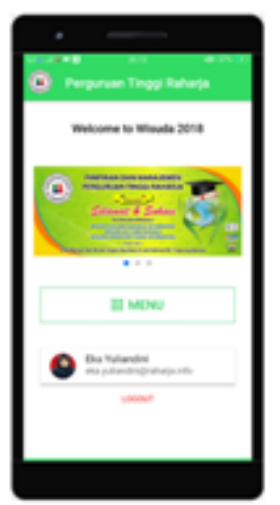

Gambar16. Halaman utama

9. Halaman menu (wisudawan)

Tampilan menu pada Mobile App. Pada tampilan tersebut terdapat menu agenda, denah, data-data wisudawan, galeri foto, video, dan menu home.

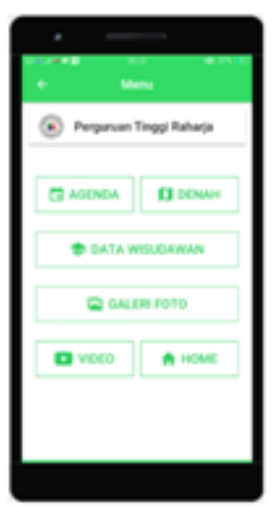

Gambar17. Halaman menu

10. Halaman agenda (wisudawan)

Tampilan halaman agenda pada Mobile App. Pada tampilan tersebut wisudawan dapat melihat susunan acara wisuda.

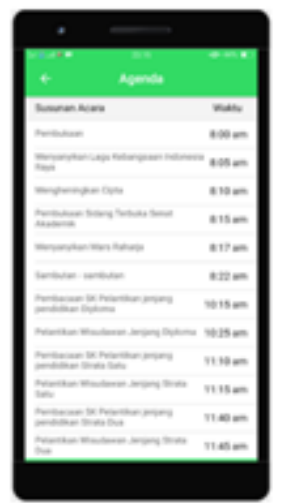

Gambar18. Halaman agenda

11. Halaman denah (wisudawan)

Tampilan halaman denah pada Mobile App. Pada tampilan tersebut wisudawan dapat melihat denah gedung wisuda. 


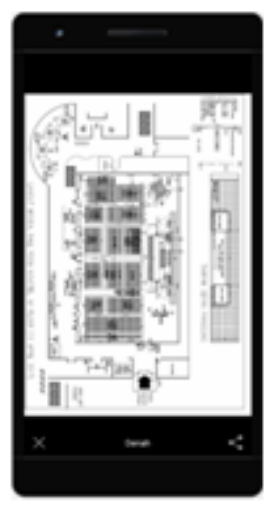

Gambar19. Halaman denah

12. Halaman data wisudawan (wisudawan)

Tampilan halaman data-data wisudawan pada Mobile App. Pada tampilan tersebut terdapat data-data wisudawan seperti nama wisudawan, NIM, jurusan, konsentrasi, dan nomor bangku.

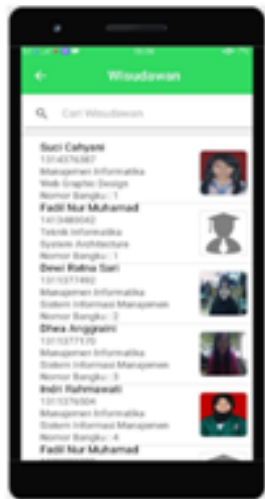

Gambar20. Halaman data wisudawan (wisudawan)

13. Halaman galeri foto (wisudawan)

Tampilan halaman galeri foto pada Mobile App. Pada tampilan tersebut wisudawan dapat melihat foto-foto wisuda.

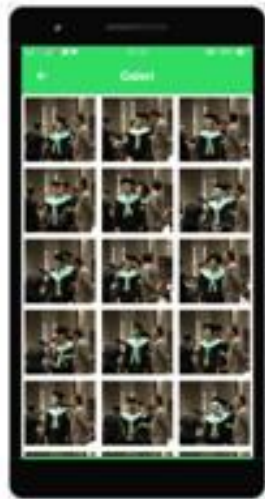

Gambar21. Halaman galeri foto

14. Halaman video (wisudawan)

Tampilan halaman video pada Mobile App. Pada tampilan tersebut wisudawan dapat melihat video wisuda. 


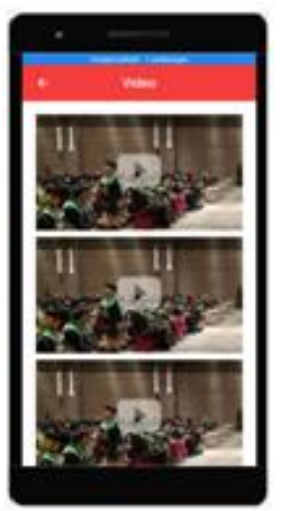

Gambar22. Halaman video

\section{KESIMPULAN}

Dari penelitian yang telah dilakukan dapat disimpulkan beberapa hal sebagai berikut :

1. Sistem yang berjalan sebelumnya mengenai wisuda hanya dapat melakukan absensi. Absensi hanya dapat dilakukan oleh admin dan hanya dapat melakukan absensi kepada wisudawan saja. Penelitian ini mengembangkan sistem absensi yang berjalan sebelumnya sehingga admin dapat melakukan absensi orang tua, tamu VIP/VVIP, serta melakukan create data wisudawan. Operator pada sistem ini juga dapat melakukan absensi orang tua, absensi tamu VIP/VVIP, serta melihat dashboard kehadiran peserta wisuda.

2. Wisudawan mengalami kendala dalam mendapakan informasi mengenai acara wisuda, karena belum adanya suatu sistem mengenai acara wisuda. Peneliti membuat suatu aplikasi online graduation organizer menggunakan suatu mobile application untuk wisudawan dalam rangka mempermudah wisudawan dalam mendapatkan informasi yang dibutuhkan mengenai acara wisuda.

3. Perancangan aplikasi online graduation organizer yang menggunakan suatu mobile application untuk acara wisuda akan mempermudah wisudawan dalam hal pengunaan. Admin dan operator akan lebih mudah melakukan akses sistem berbasis web.

\section{DAFTAR PUSTAKA}

[1] Maulani, Giandari., Kartika Chandra Buana Sejati, Siti Pujianingsih (2016) "Sistem Informasi Pengelolaan Data Pembinaan Kegiatan Kerja Narapidana Berbasis Website pada Lembaga Pemasyarakatan Kelas IIA Pemuda Tangerang”. Jurnal ICIT. Vol. 2 No. 1, Februari 2016. Tangerang : Perguruan Tinggi Raharja.

[2] Aris, Donatus., Agus Andriyanto, Yudha Surya Putra (2016) "Aplikasi Sistem Penjualan Perlengkapan Taekwondo Berbasis Online Pada Toko Sport Taekwondo Mawar Hitam Kab. Tangerang”. Jurnal SENSI. Vol. 2 No. 1 - Februari 2016. Tangerang : Perguruan Tinggi Raharja.

[3] Mulyadi (2013) "Rancang Bangun Sistem Pendaftaran Wisuda (Studi Kasus : STIKOM Dinamika Bangsa Jambi)". Jurnal Media Sistem Informasi. Vol. 7, No.3, September 2013. Jambi : STIKOM Dinamika Bangsa.

[4] Londa, Baraney Nicolas., Johny Senduk, Anthonius Boham (2014) "Efektifitas Komunikasi Antar Pribadi dalam Meningkatkan Kesuksesan Sparkle Organizer". Jurnal Acta Diurna. Volume 3. No.1. Tahun 2014. Manado : Universitas Sam Ratulangi.

[5] Utomo, Victor (2010) "Pengembangan Sistem Pengumpulan Data Menggunakan Aplikasi Mobile dan Web Service". Jurnal Teknologi Informasi dan Komunikasi. ISSN:2087-0868, Volume 1 Nomor 1 Agustus 2010. Semarang : STMIK PROVISI. 